\title{
A Young Male Patient with Subaortic Membranous Stenosis and Left Ventricular NonCompaction Cardiomyopathy: A Case Report
}

Said Abdirahman Ahmed Mohamed Farah Yusuf Mohamud (ID

Mohamed Abdullahi Mohamud

Mogadishu Somali Turkish Training and Research Hospital, Mogadishu, Somalia

Correspondence: Mohamed Farah Yusuf Mohamud

Mogadishu Somali Turkish Training and

Research Hospital, Mogadishu, Somalia

Tel +252615591689

Email m.qadar59@gmail.com

\begin{abstract}
Left ventricular noncompaction cardiomyopathy (LVNC) is a relatively rare primary genetic cardiomyopathy and increased in the frequency of detection. LVNC is characterized by prominent wall trabeculations and intertrabecular recesses that communicate with the ventricular cavity. It could be in isolated form or coexists with other congenital heart diseases including valvular heart disease. The prevalence of adult LVNC ranges from $0.01 \%$ to $0.27 \%$. This present case is a 19 -year-old male patient who presents as a cardiology outpatient with progressive dyspnea for one month. Physical examination revealed tachycardia and third heart sound on auscultation. A complete left bundle branch block was detected on electrocardiography, and chest X-ray showed an enlarged cardiac shadow (cardiomegaly). Echocardiography revealed left ventricular systolic dysfunction (LVEF: $25 \%$ ), a noncompact layer, hypertrabeculation, and subaortic membranous stenosis with P-mean of $32 \mathrm{mmHg}$. The patient had started heart failure management and scheduled cardiac resynchronization therapy (CRT) for life-saving and recommended to search for either left ventricular assist device (LVAD) or heart transplantation where he can. In conclusion, the symptoms of heart failure and cardiac arrhythmias should be considered significant in apparently healthy young patients. Besides, intensive medical treatment has indicated the implantation of cardiac resynchronization therapy (CRT) "life-saving" and advanced cases of heart transplantation.
\end{abstract}

Keywords: left ventricular noncompaction cardiomyopathy, subaortic membranous stenosis, cardiac resynchronization therapy

\section{Introduction}

Left ventricular noncompaction (LVNC), also known as "spongy myocardium", is an uncommon abnormality of the left ventricular (LV) wall of unknown etiology that results from failure of the normal compaction process of the myocardium (formation of two layers of the myocardium: the compacted and the noncompacted layer) during the first trimester and described in children as well as in adults with and without chromosomal aberrations. ${ }^{1}$ Subaortic membrane stenosis (SMS) is a circumferential fibromuscular membrane involving the anterior mitral valve leaflet or the left ventricular outflow tract (LVOT) below the aortic valve. SMS is the second most common type of aortic stenosis accounting for 14\% of LVOT obstruction, with a prevalence of $6.5 \%$ of all adult congenital heart diseases. ${ }^{2}$ The prevalence of LVNC was estimated to range between $0.01 \%$ and $0.27 \%$ reaped from two retrospective studies of patients referred for echocardiography. ${ }^{3,4}$ Here, 
we report a young male patient with subaortic membranous stenosis and left ventricular noncompaction.

\section{Case Presentation}

A 19-year-old male patient presented to the cardiology outpatient with progressive shortness of breath for one month. No family history related to cardiac disease as the parents mentioned. Effort capacity was observed in classes 2-3. Physical examination revealed tachycardia and third heart sound on auscultation. A complete left bundle branch block was detected on electrocardiography (Figure 1), and chest X-ray revealed an enlarged cardiac shadow (Figure 2). As a result of echocardiographic evaluation, the left ventricle showed a noncompact layer, hypertrabeculation, and subaortic membranous stenosis (Figure 3A-C). The ejection fraction was observed to be $25 \%$ with $\mathrm{P}$-mean of $32 \mathrm{mmHg}$ and no thrombus was detected in the heart chambers. No valvular dysfunction as well as hypertrophy. Although cardiac MRI was the golden standard to diagnose LVNC, it was not available in Somalia.
The patient was diagnosed with left ventricular noncompaction with subaortic membranous stenosis and was admitted to the cardiology department. We started heart failure treatment including furosemide $20 \mathrm{mg}$, ramipril 10 $\mathrm{mg}$, carvedilol $6.25 \mathrm{mg}$, and spironolactone $25 \mathrm{mg}$. Sacubitril/valsartan is a good drug but it was not available at that time. On day 4, shortness of breath was regressed, and exercise capacity was also improved (class 1-2). One week letter, we performed cardiac resynchronization. Although the disease is genetic related and the patient was young so for long term survival we recommended researching heart transplants as soon as possible since this procedure cannot be performed in our country.

\section{Discussion}

The first case of noncompaction was described by Bellet and Gouley (1932) after an autopsy performed on a newborn infant. ${ }^{1}$

The clinical presentations were variant from asymptomatic to progressive congestive heart failure, arrhythmias, thromboembolic events, and sudden cardiac death. ${ }^{5}$

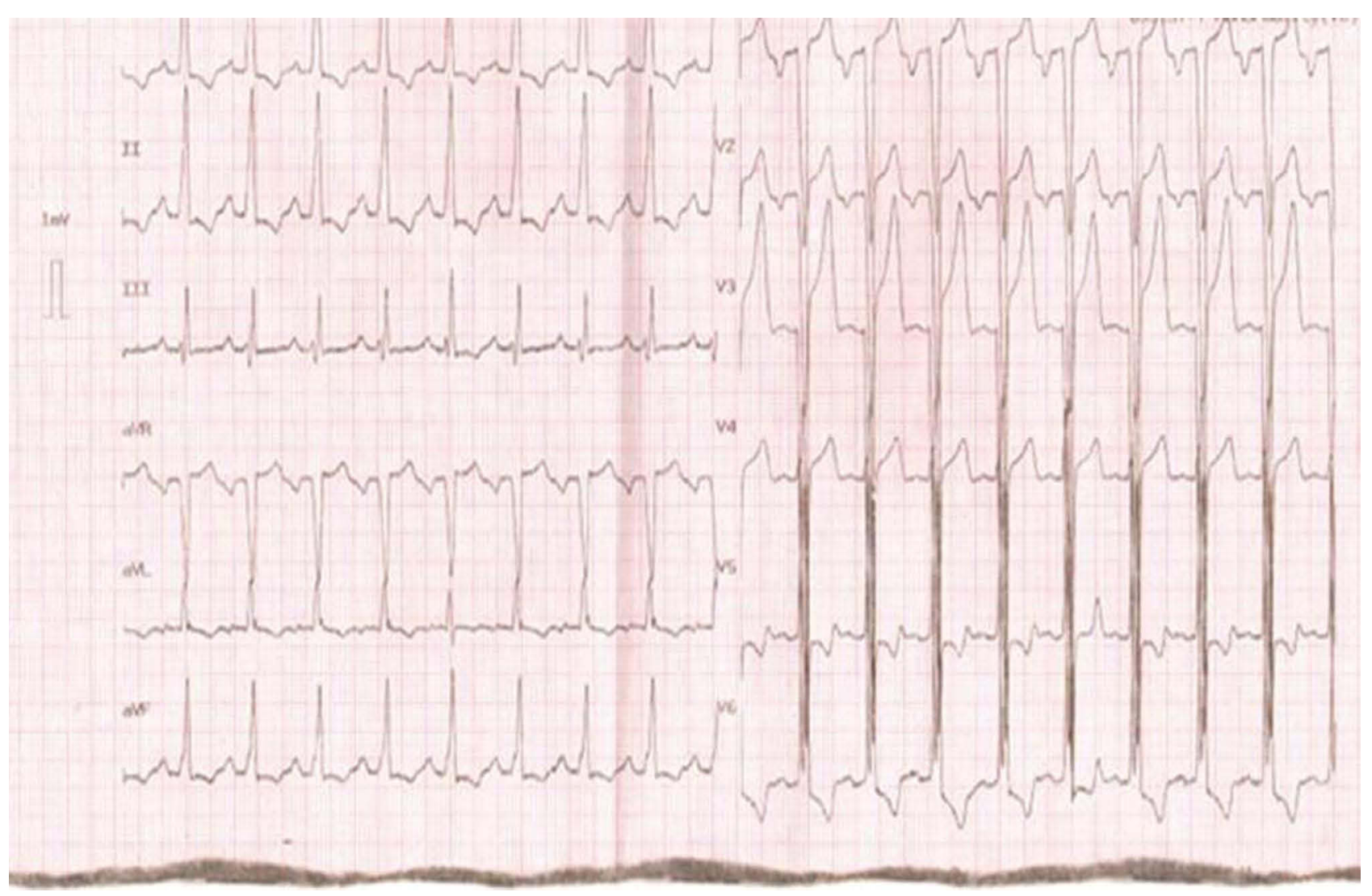

Figure I Electrocardiography: shows left ventricular hypertrophy and left bundle branch block. 


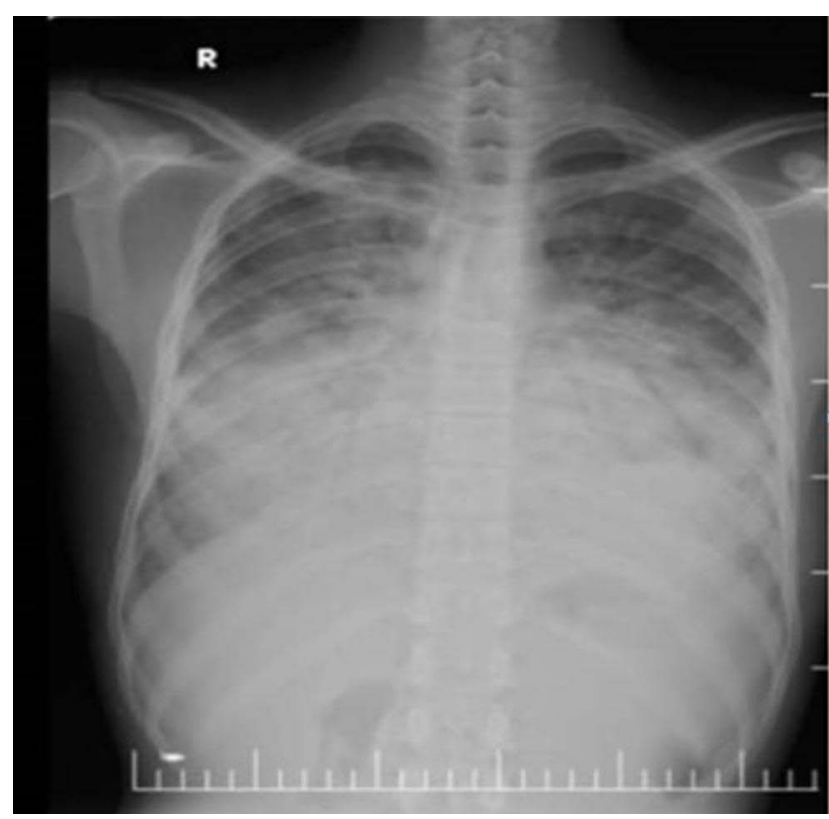

Figure 2 PA chest X-ray shows enlargement of cardiac shadow.

In the present case incomplete left bundle branch block was detected on electrocardiography, while Akhan and
Ardahanlı reported that there is significant relationship between NCCM and TPe, cTPe, TPe/QT, TPe/cQT, and cTPe/cQT parameters. ${ }^{6}$

Our case was noncompaction cardiomyopathy with the subaortic membranous stenosis, and a similar case was mentioned by Shuhaiber et al. ${ }^{7}$ In contrast to the present case, left ventricular noncompaction with bicuspid aortic valve was reported by Yang et al. ${ }^{8}$

In contrast to the present case, some patients are asymptomatic with preserved LV systolic function; others develop heart failure, thromboembolic events, and malignant arrhythmias. Systolic dysfunction and arrhythmias may be a consequence of dysfunction at the microcirculation level and subepicardial hypoperfusion. ${ }^{9}$

Coexisting valvular anomalies special subaortic membranous stenosis similar to our case is rare 2/55 (4\%), and it needs further investigation because it can be attributed to expedite the potential for adverse clinical events. ${ }^{10}$

The prognosis of patients with LVNC is poor with high mortality that exceeds $35 \%$, during the first four years after the development of symptoms in which half of the deaths
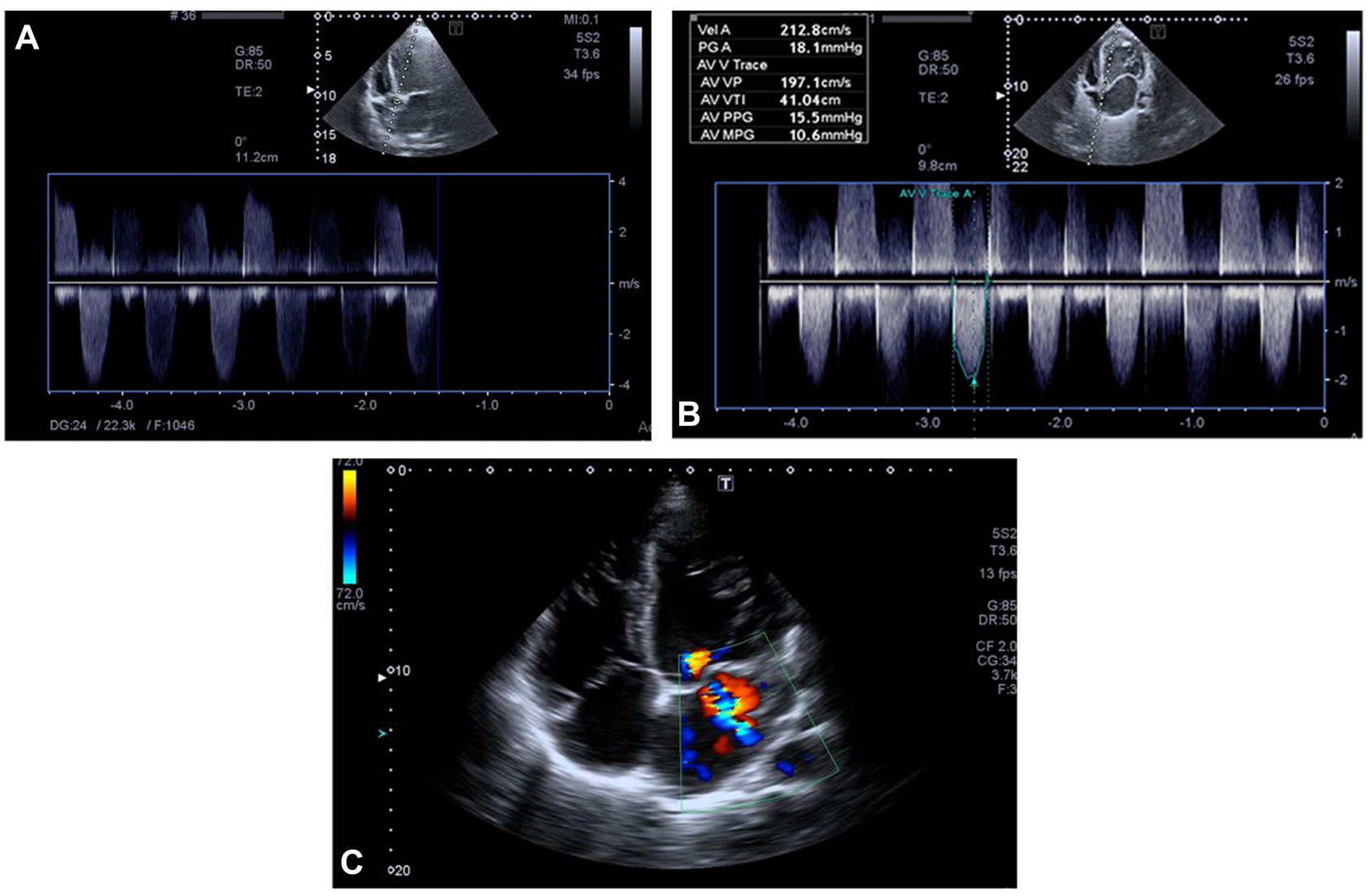

Figure 3 (A-C) Echocardiographic findings: five-chamber view of two-dimensional echocardiography obtained at the time of presentation revealed noncompaction layers of left ventricular with subaortic membranous senosis and four chamber view with Doppler. 
are sudden, therefore besides intensive medical treatment, implantation of a "life-saving" implantable cardioverter defibrillator and cardiac resynchronization therapy, and in advanced cases, heart transplantation is indicated. ${ }^{11}$ In the present case, we performed CRT as a bridging therapy to either left ventricular assist device (LVAD) or heart transplantation. Although the disease is genetic related and the patient was young so for long term survival we recommended researching heart transplants as soon as possible since this procedure cannot be performed in our country.

\section{Ethics}

Institutional approval was not required to publish the case details.

\section{Consent}

We received patient consent to publish this case report.

\section{Disclosure}

The authors report no conflicts of interest in this work.

\section{References}

1. Bellet S, Gouley BA. Congenital heart disease with multiple cardiac abnormalities: report of a case showing aortic atresia, fibrous scar in myocardium and embryonal sinusoidal remains. Am J Med Sci. 1932;183:458-465. doi:10.1097/00000441-193204000-00003

2. Oliver JM, González A, Gallego P, Sánchez-Recalde A, Benito F, Mesa JM. Discrete subaortic stenosis in adults: increased prevalence and slow rate of progression of the obstruction and aortic regurgitation. J Am Coll Cardiol. 2001;38(3):835-842. doi:10.1016/S0735-1097(01) 01464-4
3. Benjamin MM, Khetan RA, Kowal RC, Schussler JM. Diagnosis of left ventricular noncompaction by computed tomography. InBaylor Univ Med Center Proc. 2012;25(4):354-356. doi:10.1080/ 08998280.2012.11928875

4. Stöllberger C, Blazek G, Winkler-Dworak M, Finsterer J. Sex differences in left ventricular noncompaction in patients with and without neuromuscular disorders. Revista Española de Cardiología. 2008;61 (2):130-136. doi:10.1157/13116200

5. Oechslin EN, Attenhofer Jost CH, Rojas JR, Kaufmann PA, Jenni R. Long-term follow-up of 34 adults with isolated left ventricular noncompaction: a distinct cardiomyopathy with poor prognosis. $J$ Am Coll Cardiol. 2000;36:493-500. doi:10.1016/S0735-1097(00)00755-5

6. Akhan O, Ardahanlı İ. Evaluation of ventricular polarization in noncompaction cardiomyopathy with electrocardiography in a different perspective. InECM. 2020;8(4):180-185.

7. Shuhaiber J, McMahon J, Bakhos M. Surgical treatment of subaortic stenosis and noncompaction of the left ventricle. J Card Surg. 2008;23(6):688-690. doi:10.1111/j.1540-8191.2008.00702.x

8. Yang WJ, Im Kim J, Jin ES, Lee HN, Shin SY. Left ventricular noncompaction with bicuspid aortic valve: a case report with a comprehensive cardiac MRI approach. Iran J Radiol. 2019;16(3). doi:10.5812/iranjradiol.85739

9. O'Donnell DH, Abbara S, Chaithiraphan V, et al. Cardiac MR imaging of nonischemic cardiomyopathies: imaging protocols and spectra of appearances. Radiology. 2012;262(2):403-422. doi:10.1148/ radiol.11100284

10. Devabhaktuni SR, Chakfeh E, Malik AO, Pengson JA, Rana J, Ahsan CH. Subvalvular aortic stenosis: a review of current literature. Clin Cardiol. 2018;41(1):131-136. doi:10.1002/clc.22775

11. Stamou SC, Lefrak EA, Athari FC, Burton NA, Massimiano PS. Heart transplantation in a patient with isolated noncompaction of the left ventricular myocardium. Ann Thorac Surg. 2004;77 (5):1806-1808. doi:10.1016/S0003-4975(03)01292-X
Research Reports in Clinical Cardiology

\section{Publish your work in this journal}

Research Reports in Clinical Cardiology is an international, peerreviewed, open access journal publishing original research, reports, editorials, reviews and commentaries on all areas of cardiology in the clinic and laboratory. The manuscript management system is

\section{Dovepress}

completely online and includes a very quick and fair peer-review system. Visit http://www.dovepress.com/testimonials.php to read real quotes from published authors. 